\title{
Pulmonary Hypertension in Patients with Pulmonary Arteriovenous Fistulae
}

\author{
RAJENDRA P. SAPRU*, DUNCAN C. S. HUTCHISON†, AND JOHN I. HALL \\ From the Departments of Medicine and Cardiology, The Royal Infirmary, Edinburgh
}

The clinical features of pulmonary arteriovenous fistulae have been well documented (Goldman, 1948; Baer, Behrend, and Goldburgh, 1950; Giampalmo, 1950; Muri, 1953; Steinberg and McClenahan, 1955; Le Roux, 1959; Hodgson et al., 1959; Steinberg, 1961; Moyer, Glantz, and Brest, 1962; Jeresaty, Knight, and Hart, 1966), and are largely due to the right-to-left shunt which leads to arterial desaturation. Such shunts are frequently multiple, but the severity of the disorder is clearly determined by the over-all size of the shunt, rather than the number of anatomical lesions. The few haemodynamic studies reported in this condition are remarkable for the lack of any demonstrable abnormality (Maier et al., 1948; Friedlich, Bing, and Blount, 1950; Callahan, Helmholz, and Kirklin, 1956; Hodgson et al., 1959; Jeresaty et al., 1966) except perhaps for a moderate increase in cardiac output in a minority of cases (Baker and Trounce, 1949; Baer et al., 1950; Moyer et al., 1962).

We have recently investigated 4 patients with pulmonary arteriovenous fistulae. The finding of mild to moderate pulmonary hypertension in 3 of these patients prompted the present report. The first 3 of the 4 patients had hereditary haemorrhagic telangiectasis, a disorder that is known to be associated with multiple pulmonary arteriovenous fistulae (Goldman, 1948; Hodgson et al., 1959; Bergqvist, Hessén, and Hey, 1962); the fourth patient had a large solitary fistula.

\section{CASE Histories}

Case 1. A 52-year-old hairdresser had recurrent epistaxes since childhood. Multiple telangiectases over

Received December 20, 1968.

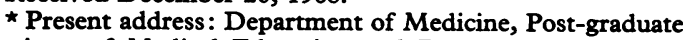
Institute of Medical Education and Research, Chandigarh, India.

† Present address: Pulmonary Research Unit, Department of Medicine, King's College Hospital Medical School, Denmark Hill, London S.E.5.

‡ Requests for reprints may be sent to John I. Hall, Department of Cardiology, The Royal Infirmary, Edinburgh. the face, tongue, palate, and buccal mucosae were first noted at the age of $\mathbf{4 0}$ years. In 1950 he had deep vein thrombosis in the left calf, and varicose veins of the lower limbs were stripped in 1953 and 1958. Ethinyl oestradiol ( $0.25 \mathrm{mg}$. daily) was started in 1963 for the control of epistaxes. Since April 1966, he had experienced several episodes of syncope on effort, and in June 1966 he had his first and only documented pulmonary infarction. Over the preceding year he had also complained of mild angina of effort, latterly accompanied by breathlessness.

The only other affected member of the family was his 13-year-old son who died suddenly, and at necropsy a large pulmonary arteriovenous fistula was demonstrated. The latter case was recorded by Ronald (1954).

When seen in June 1966 he looked pale and telangiectases were present on the face, lips, buccal mucosa, tongue, fauces, and hands. His hands were warm and cyanosed, but there was no clubbing of the fingers. Fine skin and gynaecomastia were attributed to the administration of ethinyl oestradiol. The heart was not enlarged clinically, but the pulmonary closure sound was accentuated. A variable soft systolic murmur was present over the left interscapular area.

The electrocardiogram showed sinus rhythm with asymmetrical $\mathrm{T}$ wave inversion over the right praecordial leads (Fig. 1). Chest $x$-ray showed a normal cardiac silhouette but some enlargement of the main pulmonary arteries especially the lower lobe branches (Fig. 2a). Hb $12 \cdot 1$ g. $/ 100 \mathrm{ml}$. and PCV 39 per cent. ESR was increased at $39 \mathrm{~mm}$. in the first hour. Bleeding and clotting tests were all within normal limits. The red cell mass and total blood volume were normal.

Case 2. A 52-year-old housewife had intermittent epistaxes since childhood. She first noticed dark blue spots on her face at the age of 50 years. Since her admittance to hospital for a severe epistaxis requiring blood transfusion in 1964, she had experienced dyspnoea and upper chest discomfort on exertion. Over the years the epistaxes had responded temporarily to packing, cautery, and nasal septal injections of ethanolamine. Radiotherapy was without benefit, but the frequency and severity of the epistaxes were reduced after starting ethinyl oestradiol (0.3 mg. daily) in 1964. In April 1966 , at the time of a cholecystectomy, several telangiectases on the surface of the liver were noted. 


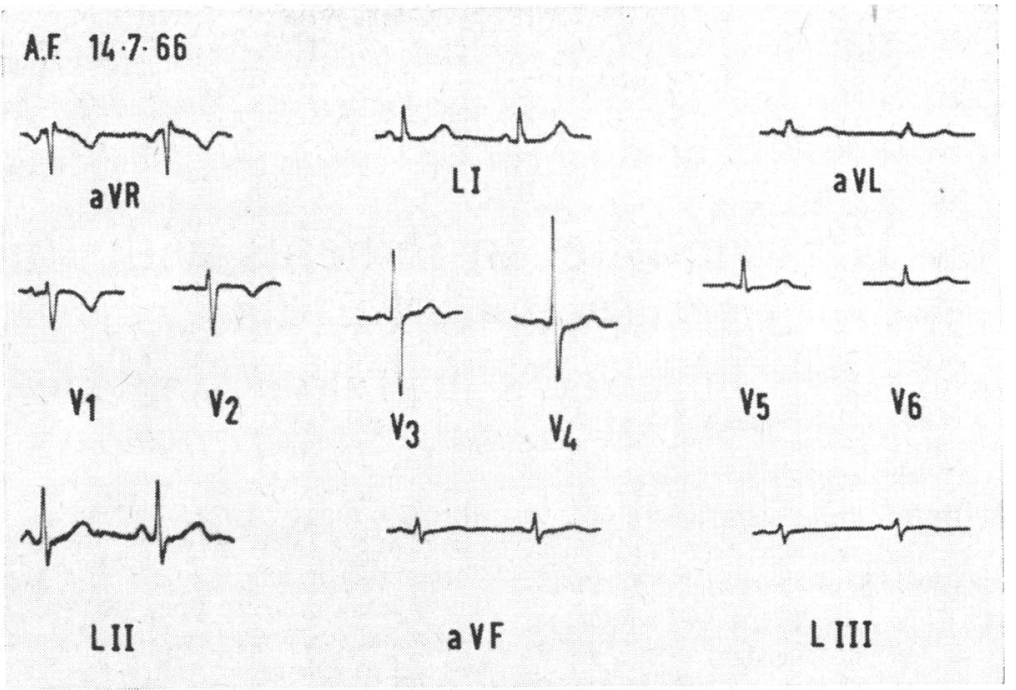

FIG. 1.-Electrocardiogram of Case 1. The frontal plane mean QRS axis is $+30^{\circ}$. $\mathrm{T}$ wave inversion is present in leads V1 and V2.

The patient's mother, a maternal uncle and aunt, and a brother also had epistaxes and telangiectases, while a 22-year-old daughter had recurrent epistaxes.

When seen in September 1966, telangiectases were evident on the face, ear lobes, mouth, tongue, hands, and fingers. There was no clinical cyanosis or clubbing. Presystolic venous pulsation was present in the neck. A right ventricular lift was felt, and the pulmonary valve closure was palpable. A late systolic murmur was audible between the lower left sternal edge and the apex; its intensity increased on inspiration. The second heart sound was normally split but the pulmonary closure sound was increased.

Electrocardiogram (Fig. 3) showed sinus rhythm, with right axis deviation, right ventricular hypertrophy, and ischaemia. Chest $x$-ray showed cardiomegaly and prominence of the main pulmonary artery; the aorta was small and the lung fields relatively ischaemic (Fig. 4). The blood count showed haemoglobin $9.4 \mathrm{~g} . / 100 \mathrm{ml}$. PCV 35 per cent, MCHC 27 per cent; other cellular elements and ESR were normal. Tests for clotting and bleeding functions were normal. Likewise other routine biochemical tests were also normal.

Case 3. A 58-year-old housewife started to have recurrent nose bleeds at the age of 30 years. Cautery on three occasions provided temporary relief. A profuse haemorrhage from the mouth at the age of 38 led to the recognition of dark blue spots on the tongue, which gradually became more numerous and involved the lips, face, and hands. Breathlessness on exertion, at times accompanied by chest tightness, developed at the age of 55 years (1963) and gradually increased. Ethinyl oestradiol ( $0.15 \mathrm{mg}$. daily) had been started in March 1966 for the control of epistaxes.

The patient's father and two brothers had recurrent epistaxes and telangiectases, as also did one 30-year-old daughter.

When seen in November 1966, there were obvious telangiectases distributed over the face, lips, tongue, pharynx, and hands. The heart sounds were normal and a short systolic murmur was audible at the apex.

The electrocardiogram was normal. Chest $x$-ray showed slight cardiomegaly, with an unfolded aorta. An irregular, well-defined lobulated mass was visible in front of the right hilum, but no vascular connexions could be seen in relation to it. Blood count showed an irondeficiency anaemia; $\mathrm{Hb} 7 \cdot 1 \mathrm{~g} . / 100 \mathrm{ml}$., PCV 27 per cent, MCHC 26 per cent. Other cellular elements of the blood and ESR were normal. The bleeding and clotting tests were normal. Following transfusion of two pints of packed cells $\mathrm{Hb}$ rose to $11 \cdot 1 \mathrm{~g} . / 100 \mathrm{ml}$.

Case 4. A 39-year-old upholsterer first noticed exertional dyspnoea in the late summer of 1965, and later also experienced occasional angina of effort. His wife had noticed that the patient's ear lobes turned blue on exertion. There had been no significant past illnesses. Family history was unremarkable.

When seen in January 1967, he was not dyspnoeic or cyanosed at rest. The fingers and toes were clubbed. There were no cutaneous or buccal telangiectases. Pulse and blood pressure were normal, as was the jugular venous pulse. A right ventricular lift was felt and pulmonary closure sound was increased in intensity but normally split. A continuous murmur could be heard all over the praecordium and maximally just below the right nipple. The intensity of the murmur increased during a Muller's manoeuvre and decreased during the strain phase of the Valsalva manoeuvre. A clinical diagnosis of a pulmonary arteriovenous fistula was made. Chest $x$-ray showed prominence of the main pulmon- 


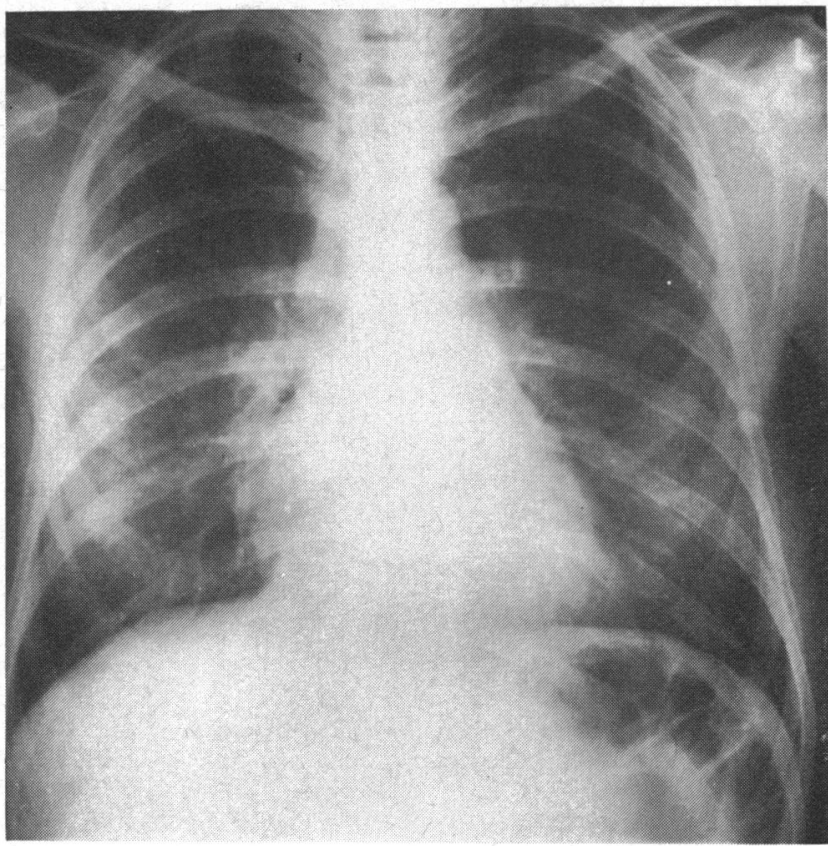

(a)

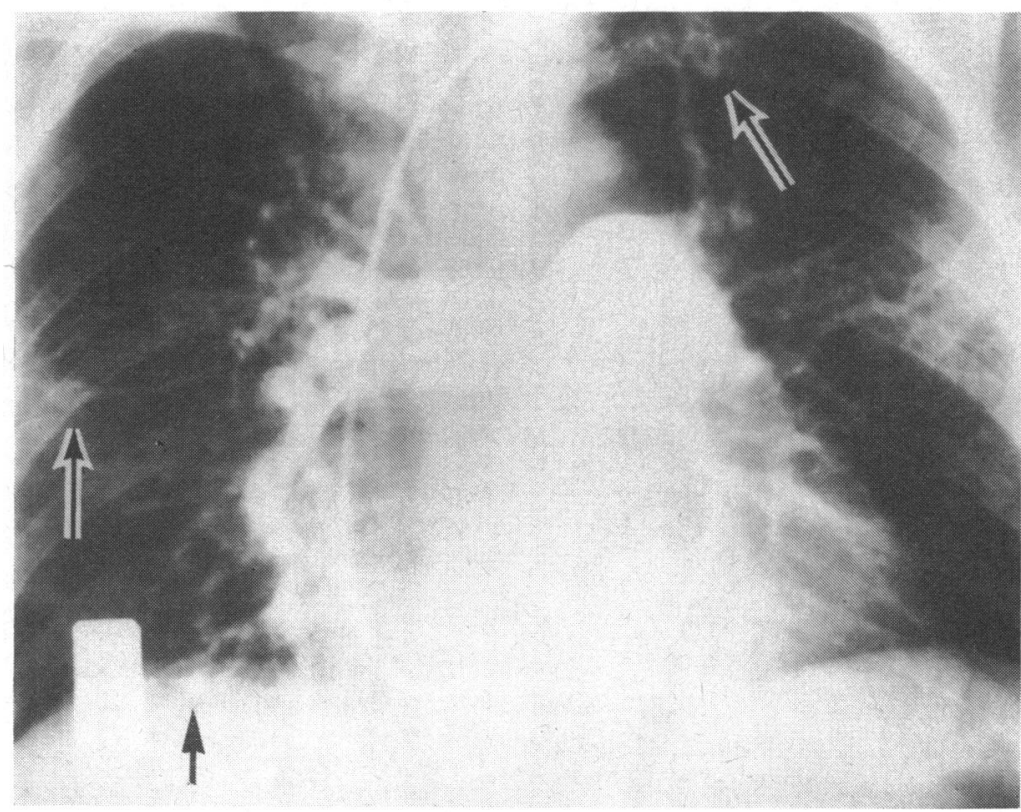

(b)

FIG. 2.-Chest $x$-ray (a) and pulmonary artery angiogram (b) of Case 1. Several globular areas of contrast with feeding vessels are seen in both lung fields. There is pruning of pulmonary arteries, especially on the left side. 


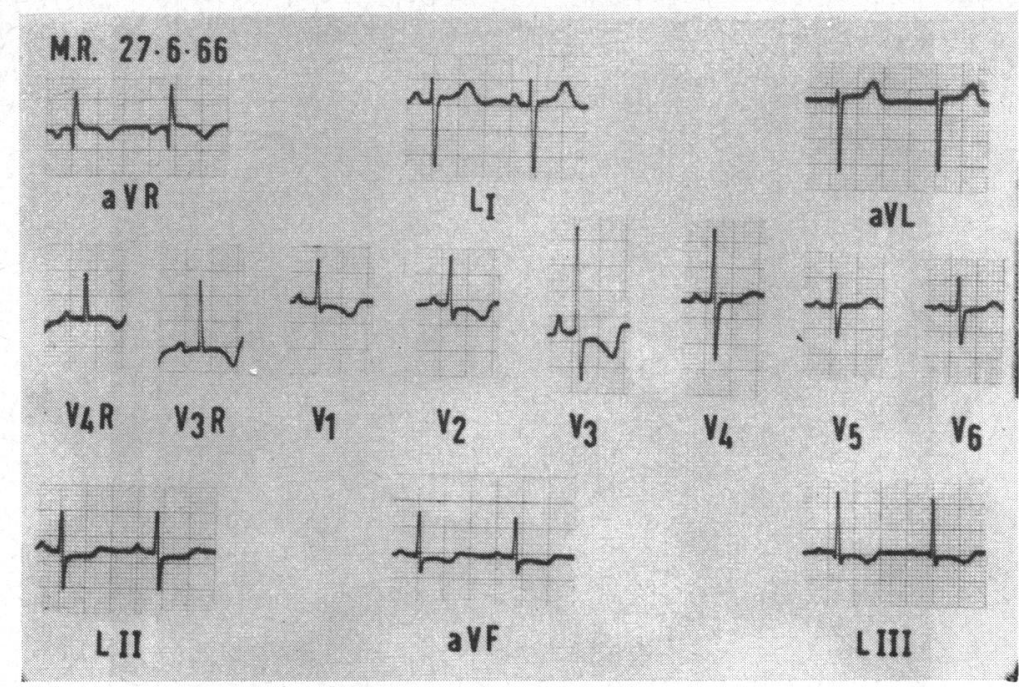

FIG. 3.-Electrocardiogram of Case 2 showing right ventricular hypertrophy and $T$ wave inversion in the right praecordial leads. The frontal plane mean QRS axis is $+150^{\circ}$.

ary artery and its principal divisions. An opacity could be seen in the right middle lobe, with well-delineated feeding and draining vessels (Fig. 5a). Pulmonary angiography revealed a single large arteriovenous fistula in the right middle lobe (Fig. 5b). The remaining lung vessels were normal. The electrocardiogram was nor-

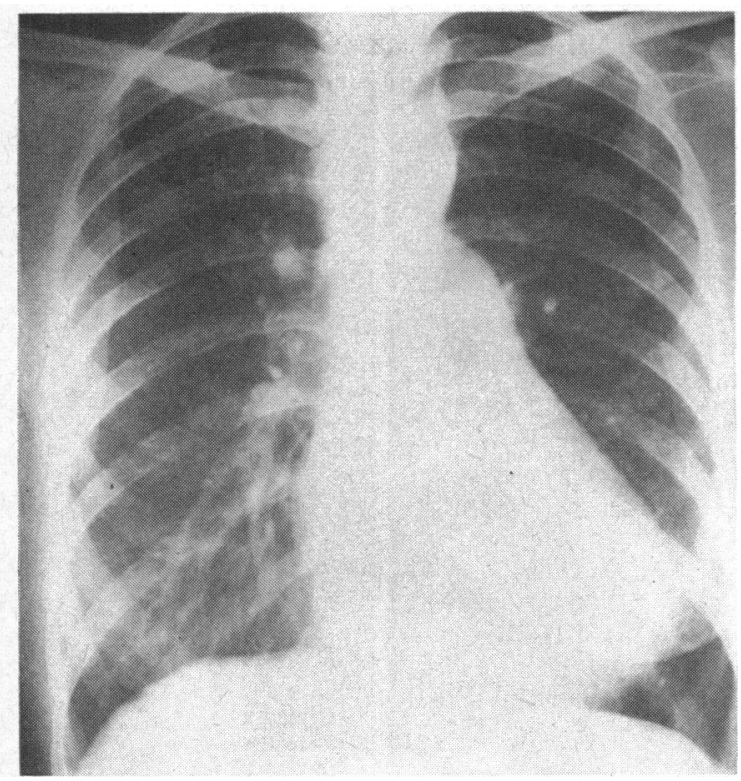

FIG. 4.-Chest $x$-ray of Case 2 showing enlargement of the pulmonary artery and relative ischaemia of the peripheral lung fields. mal. Hb $15.8 \mathrm{~g} . / 100 \mathrm{ml}$. and PCV 49 per cent. Other routine haematological and biochemical tests were normal.

Right middle lobectomy was performed, but 12 hours later he suddenly became shocked and died the following morning. At necropsy no cause for death was found. A single large arteriovenous fistula was seen in the lobe of the lung removed at operation (Fig. 5c). The remaining lung tissue examined at necropsy did not show any other arteriovenous fistulae, but marked atheromatous changes were seen in the pulmonary arteries. Histologically both large and small pulmonary artery branches showed marked intimal fibroelastic thickening and medial hypertrophy of the acquired type (Fig. 6a, b, and c). No definite intravascular thrombi were seen. The bronchial arteries and pulmonary veins did not show any abnormality.

The clinical features indicative of pulmonary hypertension and the desirability of locating the site of the fistulae in these patients prompted further investigation by cardiac catheterization and pulmonary artery angiography. A brief description of the techniques used in the first 3 patients follows. The last patient was investigated elsewhere but using essentially similar techniques.

\section{METHODS}

The investigations were divided into three parts, the first two being carried out on the same day.

Haemodynamic Investigations and Estimation of Shunts

The investigations were performed with the patients in the supine position. No prior sedation was given.

Right heart catheterization was performed, and simultaneous recordings of the pulmonary wedge, pulmonary artery, and right atrial pressures were obtained through 


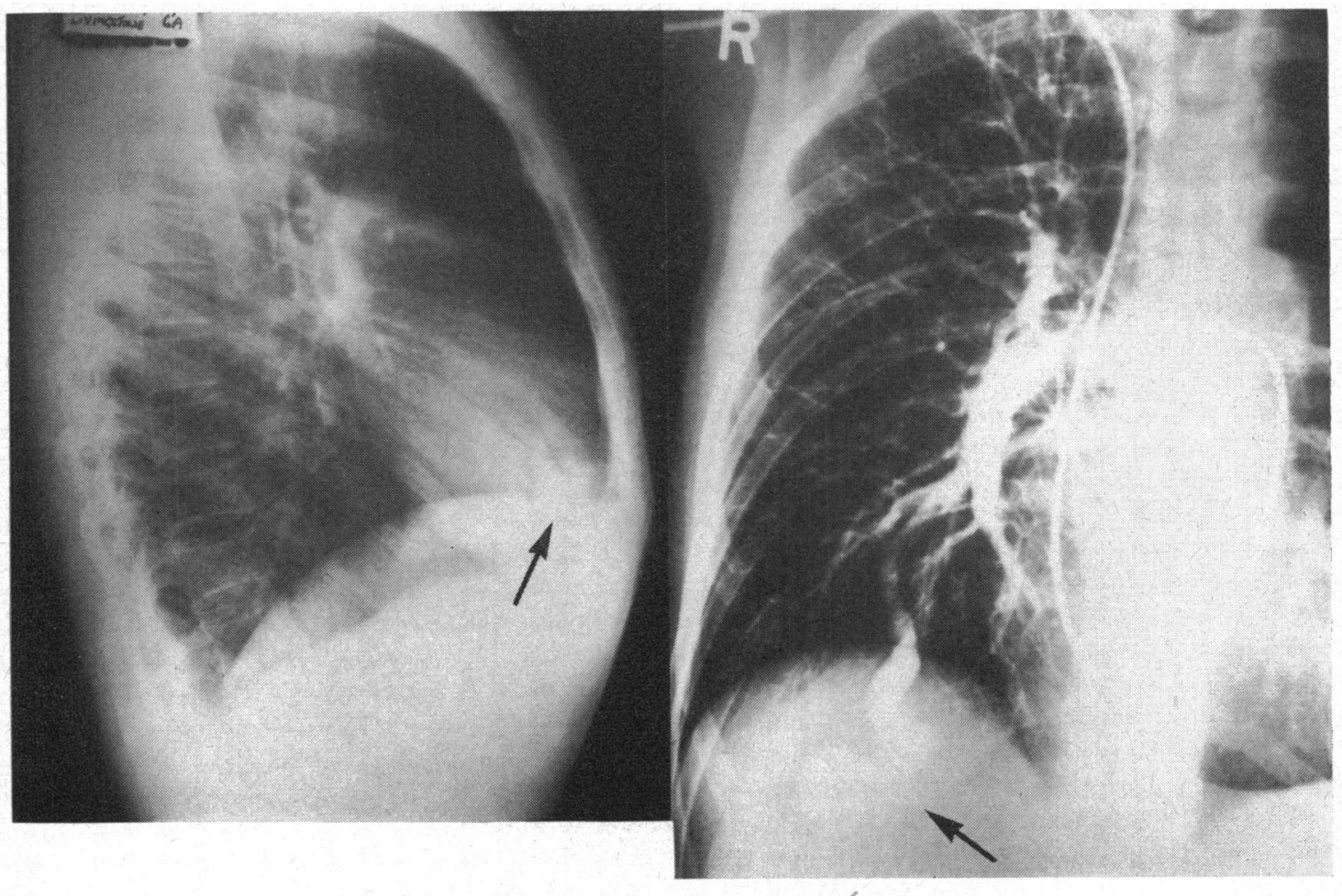

(a)

(b)

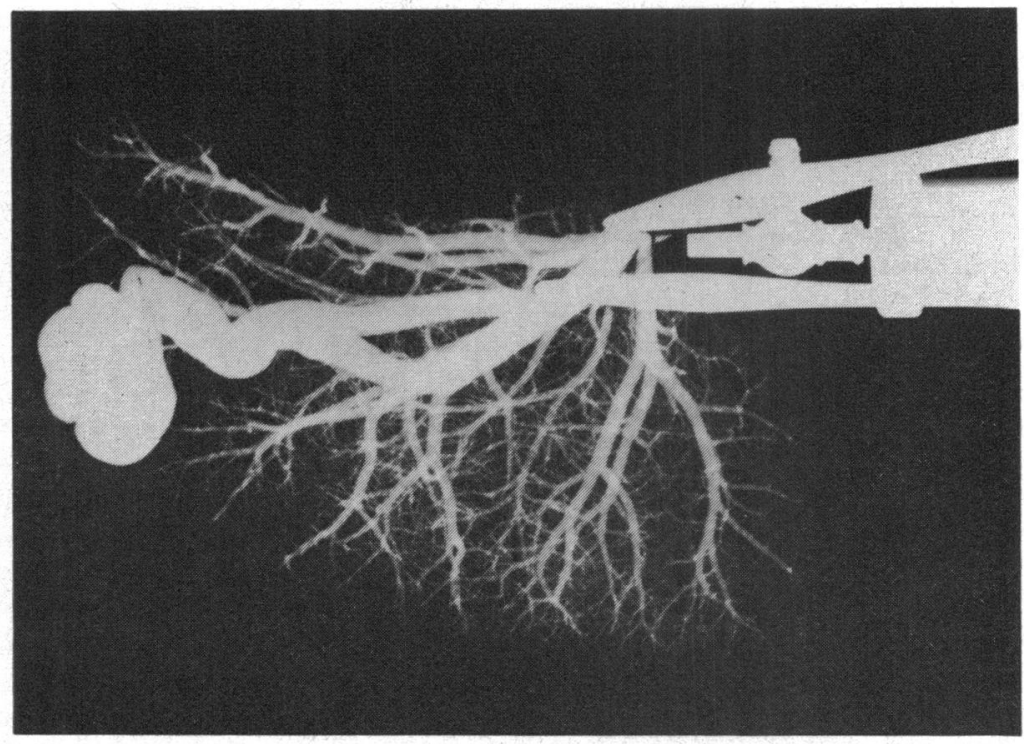

(c)

FIg. 5.-(a) Chest $x$-ray (lateral view) of Case 4 showing an opacity in the right middle lobe, with welldefined feeding and draining vessels. (b) Angiography confirmed that this was a pulmonary arteriovenous fistula. The remaining vessels appear to be perfectly normal. (c) Fistula seen on $x$-ray of the resected middle lobe. 


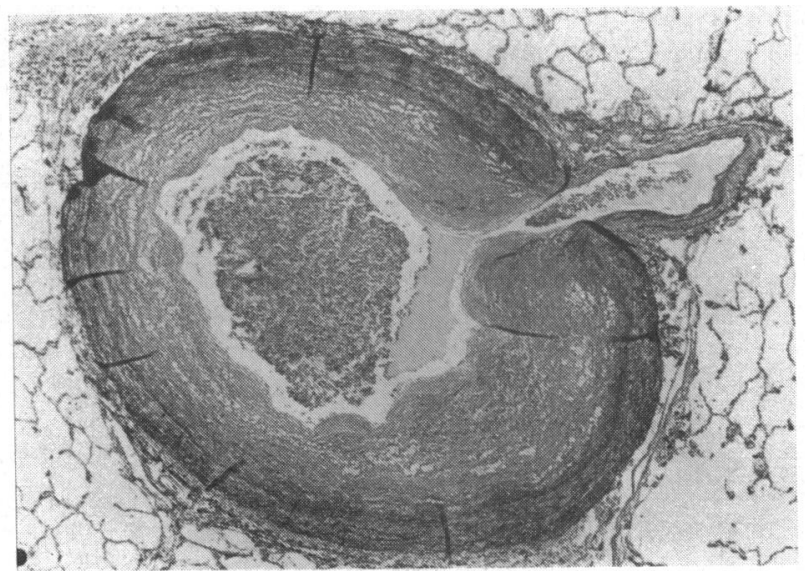

(a)

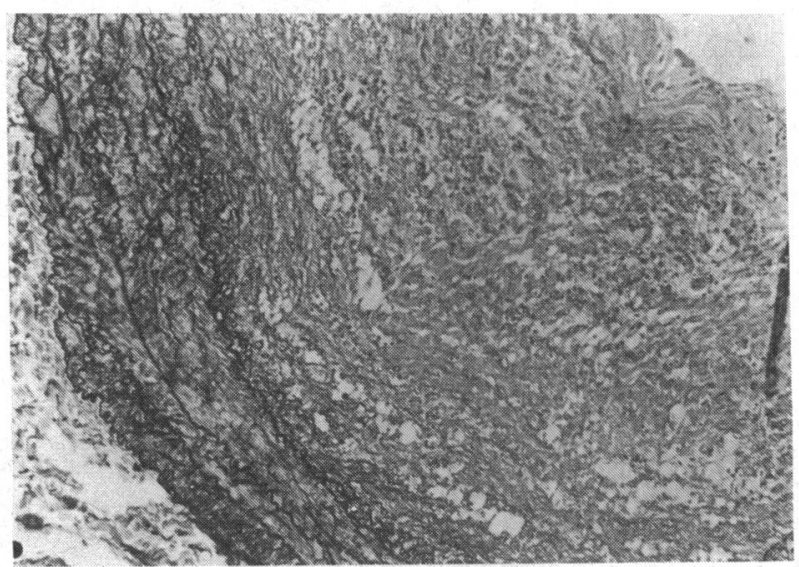

(b)

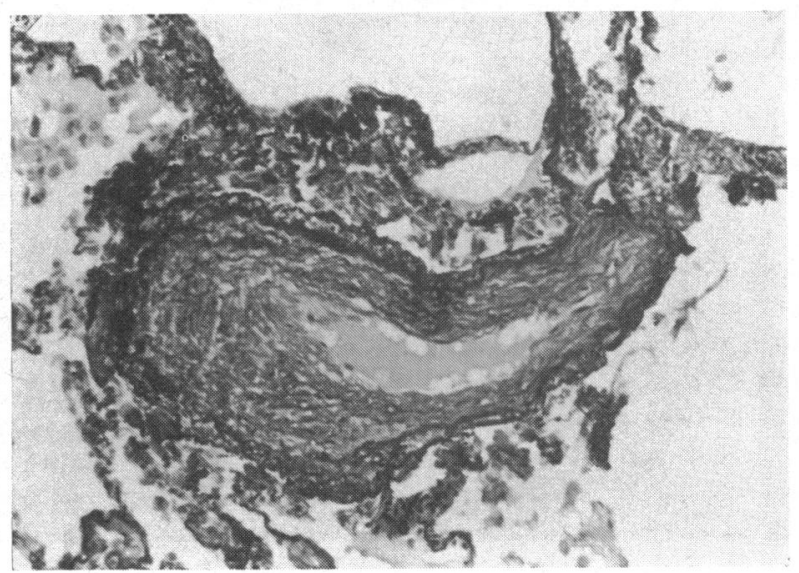

(c)

FIG. 6.-Photomicrograph showing the histological changes in the pulmonary arteries of Case 4. Sections obtained from the lung not affected by fistula formation. (a) A medium sized artery showing marked intimal hyperplasia (Elastic van Gieson. $\times 28$ ), and (b) a segment of the same vessel under higher magnification. ( $\times$ 92.) (c) A smaller artery also showing the fibrous thickening of the intima. (Elastic van Gieson. $\times 140$.) 
a quadruple lumen cardiac catheter. A $55 \mathrm{~cm}$. long nylon catheter (bore $0.8 \mathrm{~mm}$.) was also introduced percutaneously into the brachial artery by the Seldinger technique and advanced into the ascending aorta. The latter catheter was used both for recording aortic pressure and for obtaining the indicator dilution curves.

All pressures were transduced by Statham P23Db strain gauge manometers and referred to $10 \mathrm{~cm}$. above the table top; phasic and mean pressures were recorded simultaneously.

The cardiac output was measured by the indicator dilution technique, using indocyanine green dye. The dye bolus was rapidly injected $(0.4 \mathrm{sec}$.) into the main pulmonary artery and sampled from the ascending aorta through a Waters XC 300 cuvette densitometer at a constant speed of $38.2 \mathrm{ml}$./min., by means of a Harvard pump. The curves thus obtained were measured manually by the Hamilton semilogarithmic extrapolation method. All recordings were obtained on a multichannel Honeywell U-V recorder.

Arterial Blood Gases. The arterial blood oxygen tension $\left(\mathrm{P}_{\mathrm{a}} \mathrm{O}_{2}\right)$ was measured with a Clark electrode calibrated with the patients own blood equilibrated in a tonometer to a known $\mathrm{PO}_{2} . \quad \mathrm{P}_{\mathrm{a}} \mathrm{CO}_{2}$ and $\mathrm{pH}$ were measured with the Instrumentation Laboratory apparatus. Oxygen content and capacity were measured by the method of Van Slyke and Neill (1924).

Ventilation and Oxygen Consumption. Expired gas was collected in a Tissot spirometer and analysed by the Scholander method. High concentrations of oxygen (approx. 100\%) were administered by connecting a two-way non-return valve to the hospital oxygen supply. Inspired gas samples were analysed either by the Scholander method or with the oxygen electrode calibrated with known concentrations of oxygen.

Radioactive Krypton. The dose of ${ }^{85} \mathrm{Kr}$ (approximately $5 \mathrm{mCi}$ diluted in approximately $50 \mathrm{ml}$. saline) was infused into the main pulmonary artery at a rate of $0.48 \mathrm{ml}$./min., by means of a Harvard pump. During the infusion arterial blood samples were withdrawn at 5-minute intervals for 30 minutes. The standards and blood samples were counted by the method of Lassen and Munck (1955) and background counts subtracted. Mixed venous ${ }^{85} \mathrm{Kr}$ counts were obtained by appropriate calculations according to the Fick principle.

The technical details and calculations involved in the various measurements have been presented elsewhere (Sapru et al., 1969; Hutchison et al., 1968).

The plan of investigation was similar in all 3 patients. After a "steady state" had been established, as judged from the ventilation and heart rate, duplicate measurements were made over a period of 15 minutes while breathing air. Subsequently 100 per cent oxygen was administered, and at least 15 minutes were allowed to elapse before the measurements were repeated. Later ${ }^{85} \mathrm{Kr}$ was infused and further measurements made in the same manner.

\section{Pulmonary Angiography}

The quadruple lumen cardiac catheter was replaced by a $10 \mathrm{~F}$ angiographic catheter. Dehydrobenzperidol ( $5 \mathrm{mg}$.) was given intravenously for mild sedation before the injection of contrast ("Conray $60 " 1 \mathrm{ml} . / \mathrm{kg}$.) into the main pulmonary artery by means of a Gidlund pump. Serial films in the postero-anterior projection were then obtained.

\section{Lung Volumes}

Lung volumes were measured in the sitting position using a Palmer closed circuit spirometer. Functional residual capacity was measured by the helium-dilution

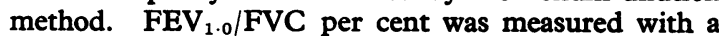
McDermott dry spirometer. Normal values were obtained from Cotes (1965).

\section{RESULTS}

Haemodynamic Data (Table I). The averages of the paired measurements during both the air and oxygen breathing periods are given in Table $I$. The cardiac output and stroke volume were within normal limits in 2 patients (Cases 2 and 3 ) and marginally depressed in the other 2 (Cases 1 and 4 ). The oxygen uptake was within normal limits in all 4 patients. The mean aortic pressure and systemic vascular resistance were slightly low especially in Case 2.

The mean pulmonary artery and right atrial pressures were raised in 3 patients and normal in 1 (Case 3). The pulmonary vascular resistance was increased in the same 3 patients and within normal limits in the fourth. The mean pulmonary wedge pressure was within normal limits in all patients.

Blood Gases (Table II). The resting $\mathrm{P}_{\mathrm{a}} \mathrm{O}_{2}$ was reduced in all patients while the $p \mathrm{H}$ was slightly increased. The $\mathrm{P}_{\mathrm{a}} \mathrm{CO}_{2}$ was low in 3 patients and normal in 1 (Case 3).

Shunt Size (Table II). The right-to-left shunt varied between 13 and 27 per cent. The ${ }^{85} \mathrm{Kr}$ infusion method was used in 2 patients, and in both of them the shunt size thus estimated was in close agreement with that obtained by the oxygen method.

Lung Volumes. The lung volumes and $\mathrm{FEV}_{1.0} /$ FVC per cent were within normal limits in all the patients.

Pulmonary Arteriograms. These were obtained in 3 patients; in view of the poor clinical state of Case 3 angiography was not performed. The angiogram of Case 1 (Fig. 2b) showed leashes of vessels running towards globular collections of contrast, 6 to $10 \mathrm{~mm}$. in diameter, which could have been arteriovenous fistulae. The main pulmonary artery was enlarged; the pulmonary artery branches were 
TABLE I

HAEMODYNAMIC DATA IN PATIENTS WITH PULMONARY ARTERIOVENOUS FISTULAE

\begin{tabular}{|c|c|c|c|c|c|c|c|c|c|c|c|c|}
\hline \multirow[t]{2}{*}{$\begin{array}{l}\text { Case } \\
\text { No. }\end{array}$} & \multirow[t]{2}{*}{ Period } & \multirow[t]{2}{*}{$\begin{array}{l}\text { Cardiac } \\
\text { output } \\
(\mathbf{l} . / \mathrm{min} . / \\
\left.\mathrm{m} .^{2}\right)\end{array}$} & \multirow[t]{2}{*}{$\begin{array}{l}\text { Heart } \\
\text { rate/ } \\
\text { min. }\end{array}$} & \multirow[t]{2}{*}{$\begin{array}{c}\text { Stroke } \\
\text { volume } \\
\left(\mathrm{ml} . / \mathrm{m} .^{2}\right)\end{array}$} & \multirow[t]{2}{*}{ 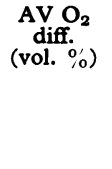 } & \multirow[t]{2}{*}{$\underset{\substack{\left.\mathrm{O}_{2} \\
\text { uptake } \\
\mathrm{ml}^{2}\right)}}{\mathrm{min}_{\mathrm{m}} /}$} & \multicolumn{4}{|c|}{ Vascular pressures. (mm. $\mathbf{H g})$} & \multicolumn{2}{|c|}{$\begin{array}{c}\text { Vascular } \\
\text { resistances } \\
\text { (dyne. sec. cm.-5 } \\
\text { m. } .^{2} \text { ) }\end{array}$} \\
\hline & & & & & & & Aorta & $\begin{array}{l}\text { Pulm. } \\
\text { wedge }\end{array}$ & $\begin{array}{l}\text { Pulm. } \\
\text { art. }\end{array}$ & $\begin{array}{c}\text { Rt. } \\
\text { atrium }\end{array}$ & Pulm. & $\underset{\text { temic }}{\text { Sys- }}$ \\
\hline \multirow[t]{2}{*}{1} & & $2 \cdot 84$ & 76 & 37 & $5 \cdot 5$ & 156 & $\begin{array}{c}107 / 68 \\
(87)\end{array}$ & (10) & $\begin{array}{c}62 / 24 \\
(36)\end{array}$ & $\begin{array}{c}a=17 \\
(12)\end{array}$ & 730 & 2450 \\
\hline & $100 \% \mathrm{O}_{2}$ & $2 \cdot 58$ & 88 & 29 & $6 \cdot 4$ & 164 & $\begin{array}{c}125 / 84 \\
(104)\end{array}$ & (9) & $\begin{array}{c}64 / 26 \\
(38)\end{array}$ & $\begin{array}{c}a=17 \\
(11)\end{array}$ & 900 & 3220 \\
\hline \multirow[t]{2}{*}{2} & Air & $4 \cdot 20$ & 78 & 54 & $3 \cdot 2$ & 134 & $\begin{array}{c}85 / 53 \\
(67)\end{array}$ & (7) & $\begin{array}{c}78 / 29 \\
(47)\end{array}$ & (15) & 760 & 1270 \\
\hline & $100 \% \mathrm{O}_{2}$ & $4 \cdot 02$ & 80 & 50 & $3 \cdot 4$ & 135 & $\begin{array}{c}97 / 63 \\
(81)\end{array}$ & (8) & $\begin{array}{c}70 / 25 \\
(43)\end{array}$ & (17) & 700 & 1610 \\
\hline \multirow[t]{2}{*}{3} & & $3 \cdot 77$ & 84 & 45 & $4 \cdot 1$ & 153 & $\begin{array}{c}117 / 67 \\
(85)\end{array}$ & (10) & $\begin{array}{c}29 / 10 \\
(18)\end{array}$ & (2) & 170 & 1800 \\
\hline & $100 \% \mathrm{O}_{2}$ & 3.65 & 80 & 46 & $4 \cdot 3$ & 155 & $\begin{array}{c}129 / 69 \\
(95)\end{array}$ & (8) & $\begin{array}{c}28 / 5 \\
(15)\end{array}$ & (4) & 150 & 2080 \\
\hline 4 & Air & $2 \cdot 42$ & 70 & 35 & $6 \cdot 6$ & 160 & $\begin{array}{c}105 / 75 \\
(90)\end{array}$ & (8) & $\begin{array}{c}86 / 35 \\
(43)\end{array}$ & $a=9$ & 1160 & 2970 \\
\hline
\end{tabular}

Figures in parentheses are mean pressures.

TABLE II

BLOOD GAS DATA AND CALCULATED SHUNT SIZE

\begin{tabular}{|c|c|c|c|c|c|c|c|}
\hline \multirow{2}{*}{ Case No. } & \multirow{2}{*}{ Period } & \multirow{2}{*}{$\mathrm{S}_{\mathrm{a}_{2}}$} & \multirow{2}{*}{$\mathbf{P}_{\mathrm{a}_{2}} \mathrm{O}_{2}$} & \multirow{2}{*}{$\mathrm{P}_{\mathrm{a}} \mathrm{CO}_{2}$} & \multirow{2}{*}{$p H$} & \multicolumn{2}{|c|}{$\begin{array}{l}\text { Calculated venous } \\
\text { admixture }(\%)\end{array}$} \\
\hline & & & & & & Oxygen & ${ }^{85} \mathrm{Kr}$ \\
\hline \multirow{2}{*}{1} & Air & 89 & 54 & 24 & $7 \cdot 48$ & 19 & \multirow{2}{*}{23} \\
\hline & $100 \% \mathrm{O}_{2}$ & 100 & 450 & 26 & $7 \cdot 46$ & 10 & \\
\hline \multirow{2}{*}{2} & Air & 89 & 56 & 32 & $7 \cdot 46$ & 27 & \multirow[b]{2}{*}{24} \\
\hline & $100 \% \mathrm{O}_{2}$ & 100 & 320 & 33 & $7 \cdot 45$ & 25 & \\
\hline \multirow{2}{*}{3} & Air & 95 & 72 & 38 & $7 \cdot 48$ & 13 & \multirow{2}{*}{-} \\
\hline & $100 \% \mathrm{O}_{2}$ & 100 & 430 & 40 & $7 \cdot 46$ & 14 & \\
\hline \multirow{2}{*}{4} & Air & 90 & 59 & 35 & $7 \cdot 45$ & 22 & \multirow{2}{*}{-} \\
\hline & $100 \% \mathrm{O}_{2}$ & 100 & 150 & 35 & $7 \cdot 45$ & 19 & \\
\hline
\end{tabular}

$\mathrm{S}_{\mathrm{a}} \mathrm{O}_{2}$, arterial oxygen saturation per cent; $\mathrm{P}_{\mathrm{a}} \mathrm{O}_{2}$, arterial oxygen tension $(\mathrm{mm} . \mathrm{Hg}) ; \mathrm{PaCO}_{2}$, arterial carbon dioxide tension $(\mathrm{mm}$. $\mathrm{Hg}$ ).

tortuous and tended to taper off abruptly. The angiogram of Case 2 also showed similar appearances suggestive of arteriovenous fistulae, but there was no evidence of pruning of the pulmonary artery branches. The solitary fistula of Case 4 was well shown (Fig. 5b); the remaining vessels appeared normal.

\section{Discussion}

The principal haemodynamic abnormality in 3 of our 4 patients was the moderate increase in pulmonary artery pressure; the raised right atrial pressure being secondary to this pulmonary hyperten- sion. Of the few published reports in which measurements of pulmonary artery pressure in patients with pulmonary arteriovenous fistulae have been made (Maier et al., 1948; Friedlich et al., 1950; Callahan et al., 1956; Le Roux, 1959; Jeresaty et al., 1966), only Case 3 of Le Roux (1959) had raised pulmonary artery pressure (mean 35 $\mathrm{mm} . \mathbf{H g}$ ).

The cause of the pulmonary hypertension in our patients is conjectural. It is possible that thromboembolism was responsible for the increased pulmonary artery pressure in Case 1; he had a clinical history of pulmonary infarction and radiological 
evidence of "pruning" of the pulmonary artery branches. However, neither of the other 2 patients (Cases 2 and 4) had any evidence to indicate a similar pathological process. While it is appreciated that clinical or laboratory evidence of thromboembolism is not always forthcoming in such patients (Goodwin, 1965), no vascular occlusions could be seen in the pulmonary arteries of the only patient (Case 4) who came to necropsy.

It is of interest that 3 of our patients (Cases 1-3) were receiving oestrogen therapy for the control of recurrent epistaxes and two of these (Cases 1 and 2) had pulmonary hypertension. However, the authors do not wish to imply any causal relation between the two observations; in fact the principal reason for including Case 3 in the present report was to indicate that there is, as yet, insufficient evidence for incriminating oestrogen therapy as the cause of pulmonary hypertension in these patients. The dosage of oestrogens was similar in all three patients receiving the drug; and, because of the small numbers, it is not possible to draw any conclusions from the differences in the duration of therapy (Case 1,

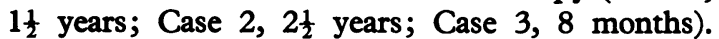
Furthermore, the fourth patient (Case 4) who had a solitary fistula and pulmonary hypertension had never received oestrogens. The possible role of oestrogen therapy in clinical thromboembolic disorders is still controversial (Pincus, 1965; World Health Organization, 1966; Medical Research Council Subcommittee Report, 1967; Brit. med. F., 1967; Lancet, 1967). Clearly an answer to this aspect of the problem must await further investigation. A comparison of the incidence of pulmonary hypertension between those patients with hereditary haemorrhagic telangiectasis receiving oestrogen therapy and those not receiving such drugs would obviously be helpful. The beneficial effect of oestrogens in the control of epistaxes in these patients is said to be due to squamous metaplasia of the nasal mucosa (Harrison, 1964).

There are two reports in which the haemodynamic changes following experimentally produced pulmonary arteriovenous fistulae in dogs have been studied (Takaro, Essex, and Burchell, 1951; Waldhausen and Abel, 1966). In acute experiments, opening of a large fistula causes a drop in the pulmonary artery pressure while the cardiac output and left atrial pressure increase linearly with the size of the shunt (Waldhausen and Abel, 1966): findings remarkably similar to those seen in systemic arteriovenous fistulae (Frank et al., 1955). On the other hand, the cardiac output in dogs some months after the creation of pulmonary arteriovenous fistulae was found to be within normal limits (Takaro et al., 1951); unfortunately no pressure measurements 4 were obtained in these animals. It would be of interest to know if the results from these acute and chronic studies represent two stages in the evolution of haemodynamic changes in this situation. Though specific data are lacking, it could be argued on theoretical grounds that the increase in the left atrial pressure caused by opening a pulmonary arteriovenous shunt might produce reflex vasoconstriction and pulmonary hypertension. This in turn would, however, increase the shunt flow unless vasoconstriction at the venous side of the shunt pathway occurred simultaneously; a fall in the mean left atrial pressure would then allow the cardiac output to return to normal levels.

The relevance of these experiments to the haemodynamic changes in pulmonary arteriovenous fistulae in man is debatable; there do not appear to be any definite clinical correlates of the experimental studies. An increased resting cardiac output has been reported in a few patients (Baker and Trounce, 1949; Baer et al., 1950; Moyer et al., 1962); the pulmonary artery pressures were normal in these patients. The cardiac outputs in our patients were normal or just below the lower limits of normal. While 3 patients had high pulmonary artery pressures, the mean pulmonary wedge pressure in all 4 (including the one with normal pulmonary artery pressures) was normal. The level of the cardiac output and pulmonary artery pressure in our patients did not appear to be related to the size of the shunt.

In patients with solitary or multiple pulmonary arteriovenous fistulae, structural abnormalities have not been found in the pulmonary vasculature other than that involved in the fistula formation (Wagenvoort, Heath, and Edwards, 1964). The only abnormality in the non-fistula containing lung of Case 4 was evidence of pulmonary hypertension of the acquired type without any indication as to its cause; the pulmonary veins and bronchial arteries were normal.

The importance of recognizing the pulmonary hypertension in these patients is fourfold. First, the recognition and investigation of this complication, whatever the aetiology, will allow a better understanding of the physiological changes in these patients. Breathlessness and syncope on effort are their common complaints, and these may be too readily put down to the coexistent anaemia in most of the patients. Secondly, operative interference in such patients may be hazardous; by closing the low resistance channels the increased vascular resistance of the remaining lung vessels may in fact produce a more severe pulmonary hypertension. It is possible that the sudden death of Case 4 was in some measure due to this compli- 
cation. Thirdly, it will be of interest to know if the pulmonary hypertension is progressive, and if so what happens to the relative volume of the shunt flow? Fourthly, the management of these patients presents a dilemma; anticoagulants may be indicated if the pulmonary hypertension is progressive but this would obviously increase the risk of haemorrhage. Two of our patients (Cases 1 and 2) have been maintained on anticoagulants so far.

The diagnosis of pulmonary arteriovenous fistulae in our patients, especially the first three, is based on the results of physiological studies and deserves some comment. Perhaps the most sensitive method for the detection of such shunts is the measurement of the alveolar-arterial oxygen tension (A-a) gradient breathing 100 per cent oxygen (McIlroy, 1965). In normal subjects in the supine position this shunt should not exceed 1.5 per cent (SD 1.9\%) of the cardiac output (Cole and Bishop, 1963). In our patients the estimated shunt varied between 13 and 27 per cent.

In 2 of our patients the shunt was also measured using an infusion of ${ }^{85} \mathrm{Kr}$; the calculations involved and the details of the methods as used in this laboratory have been presented elsewhere (Hutchison et al., 1968). As in the latter study, there was a close agreement in the estimation of the shunt size by the two methods.

Both the oxygen and ${ }^{85} \mathrm{Kr}$ methods do not, however, distinguish between true anatomical fistulae and $\dot{V} / \dot{Q}$ abnormalities when unventilated lung is perfused. There is no reason to believe that any of our patients, except perhaps Case 1 (see above), was perfusing unventilated lung, nor was there any evidence of an intracardiac shunt. Moreover, pulmonary angiograms in our patients showed vascular abnormalities which were almost certainly arteriovenous fistulae. Whereas pulmonary angiography is invaluable in the identification and location of such anomalies (Seaman and Goldman, 1952; Steinberg and McClenahan, 1955; Hodgson et al., 1959; Le Roux, 1959; Britt, Andrews, and Klassen, 1961), the lesions may, in some instances, be so small as to escape detection by this method (Hales, 1956; Cooley and McNamara, 1954).

Indicator dilution curves provide yet another method for the detection of pulmonary arteriovenous fistulae (Callahan et al., 1956). When a single large channel (or several small channels) carries preferentially a sufficiently large flow the distribution of transit times of the indicator particles (and blood) will be bimodal, giving rise to the characteristic "hump" on the upstroke of the dye curve. However, if the alveolar and shunt pathways have a wide range of transit times with considerable overlap the over-all variance of the transit times will be in- creased, as when mitral and aortic regurgitation are present, without acquiring a bimodal distribution (R. P. Sapru, unpublished observations). The dye curves in the first three of our patients did not show a "hump" on the upstroke, but the appearance time in all of them was shortened relative to the mean passage time, giving a ratio of 1.25 in Case 3,1.33 in Case 1, and 1.38 in Case 2 (upper limit of normal 0.9). Bosher, Blake, and Byrd (1959) found a very wide range of numbers, size, and distribution of AV fistulae in the lungs in various patients with hereditary haemorrhagic telangiectasis. The first three patients of this report also fall into this category. Only true anatomical shunt pathways and not $\dot{v} / \dot{Q}$ abnormalities will affect the indicator dilution curves.

\section{SUMMARY}

The results of circulatory and blood gas studies in 4 patients with pulmonary arteriovenous fistulae have been described. Three had hereditary haemorrhagic telangiectasis, while the fourth had a large solitary fistula. Haemodynamic studies showed that 3 patients had mild to moderate pulmonary hypertension, a feature previously reported only rarely in such cases. In these patients the pulmonary vascular resistance was increased, while the pulmonary wedge pressure remained normal. One patient with hereditary haemorrhagic telangiectasis did not have pulmonary hypertension. All our patients had a right-to-left shunt which varied between 13 and 27 per cent of the cardiac output. The cause of the pulmonary hypertension remains unknown, but various possibilities have been discussed. At necropsy the lungs in one of the patients who died after operation did not show any specific cause for the pulmonary hypertension.

We are grateful to Dr. R. M. Marquis, Mr. R. J. M. McCormack, and Dr. J. H. Croom for allowing us to study patients under their care. Dr. R. S. McNeill, Maryfield Hospital, Dundee, did some of the physiological studies, Dr. D. G. Julian did the catheterization, and Mr. R. J. M. McCormack performed the operation on Case 4. Dr. B. E. Heard carried out the necropsy examination on this patient. We are much obliged to Professor C. V. Harrison of the Royal Postgraduate Medical School, London, for his opinion on the histological sections and very helpful advice with regard to the paper. Investigations were done in the laboratories of the Department of Medicine, the Royal Infirmary, Edinburgh, and we are grateful to Professor K. W. Donald for his guidance. We should also like to thank Sister M. G. Mitchell, her nursing staff, and the technical staff of the Department of Medicine for their help. 


\section{REFERENCES}

Baer, S., Behrend, A., and Goldburgh, H. L. (1950). Arteriovenous fistulas of the lungs. Circulation, 1, 602.

Baker, C., and Trounce, J. R. (1949). Arteriovenous aneurysm of the lung. Brit. Heart F., 11, 109.

Bergqvist, N., Hessén, I., and Hey, M. (1962). Arteriovenous pulmonary aneurysms in Osler's disease (telangiectasia hereditaria haemorrhagica): report of four cases in the same family. Acta med. scand., 171, 301.

Bosher, L. H., Jr., Blake, D. A., and Byrd, B. R. (1959). An analysis of the pathologic anatomy of pulmonary arteriovenous aneurysms with particular reference to the applicability of local excision. Surgery, 45, 91.

Brit. med. f. (1967). Leading article. Oral contraceptives and thromboembolic disease. 2, 327.

Britt, C. I., Andrews, N. C., and Klassen, K. P. (1961). Pulmonary arteriovenous fistula. Amer. F. Surg., 101, 727.

Callahan, J. A., Helmholz, H. F., Jr., and Kirklin, J. W. (1956). Pulmonary arteriovenous fistula located by indicator dilution studies. Amer. Heart f., 52, 916.

Cole, R. B., and Bishop, J. M. (1963). Effect of varying inspired $\mathrm{O}_{2}$ tension on alveolar-arterial $\mathrm{O}_{2}$ tension difference in man. F. appl. Physiol., 18, 1043.

Cooley, D. A., and McNamara, D. G. (1954). Pulmonary telangiectasia: report of case proved by pulmonary biopsy. F. thorac. Surg., 27, 614.

Cotes, J. E. (1965). Lung Function: Assessment and Application in Medicine. Blackwell, Oxford.

Frank, C. W., Wang, H.-H., Lammerant, J., Miller, R., and Wégria, R. (1955). An experimental study of the immediate hemodynamic adjustments to acute arteriovenous fistulae of various sizes. $\mathcal{F}$. clin. Invest., 34, 722.

Friedlich, A., Bing, R. J., and Blount, S. G., Jr. (1950). Physiological studies in congenital heart disease. IX. Circulatory dynamics in the anomalies of venous return to the heart including pulmonary arteriovenous fistula. Bull. Fohns Hopk. Hosp., 86, 20.

Giampalmo, A. (1950). The arteriovenous angiomatosis of the lung with hypoxaemia. Acta med. scand., 139, Suppl. 248.

Goldman, A. (1948). Arteriovenous fistula of the lung. Amer. Rev. Tuberc., 57, 266.

Goodwin, J. F. (1965). Clinical diagnosis of pulmonary thromboembolism. In Pulmonary Embolic Disease, pp. 239-255. Ed. by A. A. Sasahara and M. Stein. Grune and Stratton, New York.

Hales, M. R. (1956). Multiple small arteriovenous fistulae of the lungs. Amer. F. Path., 32, 927.

Harrison, D. F. N. (1964). Familial haemorrhagic telangiectasia: 20 cases treated with systemic oestrogen. Quart. f. Med., 33, 25 .

Hodgson, C. H., Burchell, H. B., Good, C. A., and Clagett, O. T. (1959). Hereditary hemorrhagic telangiectasia and pulmonary arteriovenous fistula. New Engl. $\mathcal{F}$. Med., 261, 625.

Hutchison, D. C. S., Sapru, R. P., Sumerling, M. D., Donaldson, G. W. K., and Richmond, J. (1968). Cirrhosis, cyanosis and polycythaemia: multiple pulmonary arteriovenous anastomoses. Amer. F. Med., 45, 139.
Jeresaty, R. M., Knight, H. F., and Hart, W. E. (1966). Pulmonary arteriovenous fistulas in children: report of two cases and review of literature. Amer. F. Dis. Child., 111, 256.

Lancet (1967). Annotation. Thrombosis and suppression of lactation. 2, 295.

Lassen, N. A., and Munck, O. (1955). The cerebral blood flow in man determined by the use of radioactive krypton. Acta physiol. scand., 33, 30.

Le Roux, B. T. (1959). Pulmonary arteriovenous fistulae. Quart. F. Med., 28, 1.

McIlroy, M. B. (1965). Pulmonary shunts. In Handbook of Physiology, Section 3: Respiration, Vol. 2, pp. 15191524. Ed. by W. O. Fenn and H. Rahn. American Physiological Society, Washington, D.C.

Maier, H. C., Himmelstein, A., Riley, R. L., and Bunin, J. J. (1948). Arteriovenous fistula of the lung. f. thorac. Surg., 17, 13.

Medical Research Council Subcommittee Report (1967). Risk of thromboembolic disease in women taking oral contraceptives: a preliminary communication to Medical Research Council by a subcommittee. Brit. med. $\mathcal{f}$., 2, 355.

Moyer, J. H., Glantz, G., and Brest, A. N. (1962). Pulmonary arteriovenous fistulas: physiologic and clinical considerations. Amer. F. Med., 32, 417.

Muri, J. (1953). Arterio-venous aneurysms of the lung. Dis. Chest, 24, 49.

Pincus, G. (1965). The Control of Fertility, pp. 277-282. Academic Press, New York.

Ronald, J. (1954). Pulmonary arterio-venous fistula. Brit. Heart f., 16, 34.

Sapru, R. P., Lahiri, B., Hutchison, D. C. S., and Donald, K. W. (1969). Haemodynamic changes following intravenous administration of morphine sulphate. Submitted for publication.

Seaman, W. B., and Goldman, A. (1952). Roentgen aspects of pulmonary arteriovenous fistula. Arch. intern. Med., 89, 70.

Steinberg, I. (1961). Diagnosis and surgical treatment of pulmonary arteriovenous fistula: report of three new and review of nineteen consecutive cases. Surg. Clin. N. Amer., 41, 523.

_- , and McClenahan, J. (1955). Pulmonary arteriovenous fistula: angiographic observations in 9 cases. Amer. $\mathcal{F}$. Med., 19, 549.

Takaro, T., Essex, H. E., and Burchell, H. B. (1951). Experimental pulmonary arteriovenous fistula. Amer. $\mathcal{F}$. Physiol., 165, 513.

Van Slyke, D. D., and Neill, J. M. (1924). The determination of gases in blood and other solutions by vacuum extraction and manometric measurement. 1. F. biol. Chem., 61, 523.

Wagenvoort, C. A., Heath, D., and Edwards, J. E. (1964). The Pathology of the Pulmonary Vasculature. Charles C. Thomas, Springfield, Illnois.

Waldhausen, J. A., and Abel, F. L. (1966). The circulatory effects of pulmonary arteriovenous fistulas. Surgery, $59,76$.

World Health Organization (1966). Clinical aspects of oral gestogens: Report of a WHO Scientific Group. Wld Hlth Org. techn. Rep. Ser., No. 326. 